\title{
Mid-Infrared Spectroscopy as a Potential Tool for Reconstructing Lake Salinity
}

\author{
Laura Cunningham ${ }^{1, *}$, John Tibby ${ }^{2}$, Sean Forrester ${ }^{3}$, Cameron Barr ${ }^{2}$ and Jan Skjemstad ${ }^{3}$ \\ 1 Department of Geography, University of Portsmouth, Portsmouth PO1 3HE, UK \\ 2 Geography, Environment and Population and Sprigg Geobiology Centre, University of Adelaide, \\ Adelaide SA 5005, Australia; john.tibby@adelaide.edu.au (J.T.); cameron.barr@adelaide.edu.au (C.B.) \\ 3 CSIRO Land and Water, Urrbrae SA 5064, Australia; Sean_Forrester@Outlook.com (S.F.); \\ jskjemst@tpg.com.au (J.S.) \\ * Correspondence: laura.cunningham@port.ac.uk; Tel.: +44-2392-842513
}

Academic Editor: Maria Filomena Camões

Received: 29 June 2016; Accepted: 10 October 2016; Published: 26 October 2016

\begin{abstract}
Many aquatic ecosystems in Australia are impacted or threatened by salinisation; however, there is a paucity of records detailing the changes in salinity of individual water bodies that extend beyond a few decades. One way to overcome this issue is the use of inference models, which have typically been based on biological proxies. This pilot project investigates the potential for mid-infrared spectroscopy (MIRS) to provide an alternative method of reconstructing past salinity levels in Australian lakes. A small (19 lakes) calibration dataset was used to develop a MIRS-based lake water salinity inference model (measured vs. inferred salinity, based on leave-one-out cross-validation, $\mathrm{R}^{2}=0.64$ ). This model and a previously published diatom-salinity model were both used to infer salinity levels in Tower Hill Lake in south-eastern Australia, over the last 60 years. Comparisons between these reconstructions and measured salinity data from Tower Hill Lake indicate that salinities inferred by the MIRS model more closely resembled the measured values than those produced using the diatom model, predominantly in terms of the actual values inferred, but also with regard to the trends observed. This supports the hypothesis that MIRS can provide a valuable new tool for reconstructing lake salinity.
\end{abstract}

Keywords: salinity; lake sediments; southern Australia; palaeolimnology; infrared spectroscopy; diatoms; palaeoecology

\section{Introduction}

Salinity is a leading cause of soil degradation in Australia, resulting from alterations to land use, particularly vegetation clearance. In Australia, salinity has major economic and environmental impacts; over 2 million hectares of land is already affected by dryland salinity, whilst a further 3.7 million hectares has a high potential to be affected [1]. Without successful intervention, this is likely to increase to 17 million hectares by 2050 [2]. Many aquatic ecosystems in Australia are also impacted or threatened by salinisation [3,4]. For example, increasing salinity has already halved the number of bird species present in Western Australian wetlands [5]. However, long-term monitoring data are not available for the majority of Australian wetlands and lakes. Such information is important for understanding the extent and degree of lake salinisation induced by land-use change, establishing realistic remediation targets, and for inferring past climate, particularly in non-outlet lake systems. Consequently, alternative methods, such as palaeolimnology, are required to improve understanding of salinity within Australia [6,7].

Palaeolimnological methods that quantify past environmental conditions predominantly rely on the development of spatial calibration models. Within this paper, the term "spatial calibration model" 
refers to a multivariate regression model (typically using partial least-squares regression) used to determine the relationships between: (1) the value of the proxy in sediment samples from a number of different lakes or wetlands across a large spatial area; and (2) selected physical and chemical parameters from the same waterbodies, sampled at the time of sediment collection. Such predictive calibration models rely on the assumption that the processes responsible for differences over a spatial gradient will also be applicable for changes that have occurred over time. Furthermore, these models will only be accurate if the variable of interest (e.g., salinity) is the environmental factor that has the strongest influence on the selected proxy [8].

A number of studies have previously developed quantitative reconstructions of salinity within Australia, predominantly using spatial calibration models based on diatom and ostracod assemblages [9-15]. There are, however, a number of difficulties associated with some of these. For example, although diatom-based models have often been used to quantify past salinity levels overseas, in Australia their applicability is frequently limited by the impact of land-use changes, as diatoms are also sensitive to water quality shifts associated with land-use change [16]. Diatom-based inference models can also be hampered by poor diatom preservation in many Australian wetlands [17]. Taphonomic problems such as preferential transportation, different settling rates, and varying susceptibility to breakage or dissolution can also reduce the accuracy of diatom reconstructions. Finally, even when considering recent sediments that are not subject to the above issues, significant disparities between diatom inferred values and monitoring data may still be observed [18]. Such issues can also apply to other biological proxies used to infer past changes in salinity within Australian waterways. For example, distinct differences between living foraminiferal communities and the assemblages preserved within sediments have been reported [19], and differential dissolution of ostracods dependent on both on carapace morphology and the sedimentary microenvironment has also been observed [20]. Consequently, there is a need to develop a new, alternative method of determining past salinity levels.

Mid-infrared spectroscopy (MIRS) offers several advantages over more traditional reconstructions based on species assemblage data of biological proxies. Acquisition of the spectral data is rapid and several hundred samples can be measured in one day. The rapid rate of measurement, combined with the low cost of this method, allows for a greater number of sediment samples to be analysed given the same temporal and financial constraints [21-23]. Consequently, higher resolution studies and increased replication of samples are possible. Furthermore, less specialised knowledge and training are required, relative to species identification and taxonomy. Accordingly, MIRS represents a promising alternative to more costly and labour-intensive analyses of biological community assemblages.

The basic principle of MIRS is that infrared radiation stimulates molecular vibrations and, as a consequence of the quantum mechanical behaviour, this radiation is absorbed at specific wavenumbers. The wavelengths that this energy is absorbed at correspond to molecular vibrations [24]. Consequently, the wavelengths at which the MIRS radiation is absorbed can provide information about the molecular structure of the sample [25]. As every molecule has a unique chemical composition, it also has a unique infrared spectrum. Lake sediments consist of biogenic material derived from organisms formerly living in a lake and its catchment, as well as minerogenic material eroded from surrounding soils [26]. MIRS spectra of sediment consist of a combination of spectral signatures from all these components. The use of predictive calibration models provides one means of disentangling this information and extracting both qualitative and quantitative information about lake sediments and the conditions that create them. MIRS is often used in soil science where predictive models enable a wide range of chemical parameters (Table 1) [17,20-23,26-30] to be reliably determined more quickly and cheaply than traditional analyses [31,32]. Given that MIRS can be used to quantify a range of variables in dried soils, it should be equally suitable for inferring similar properties of dried lake sediments. 
Table 1. Existing IR based models derived from sediments compared to a selection of published models for similar parameters in soils. A full summary of mid-infrared (MIR) calibration models developed for soils is beyond the scope of this paper. The analytical method is shown in brackets where different analytical methods have been used for the one element or compound.

\begin{tabular}{|c|c|c|c|c|c|}
\hline \multicolumn{3}{|l|}{ Soils } & \multicolumn{3}{|c|}{ Lake or Marine Sediments } \\
\hline Parameter & $\mathbf{R}^{2}$ & Reference & Parameter & $\mathbf{R}^{2}$ & Reference \\
\hline \multirow{4}{*}{$\begin{array}{l}\text { Organic Matter } \\
\text { Organic Carbon }\end{array}$} & 0.98 & [27] & \multirow{4}{*}{ Organic Carbon } & $0.43-0.66^{1,2}$ & [33] \\
\hline & 0.73 & [28] & & 0.82 & [34] \\
\hline & $0.83-0.92$ & [29] & & $0.84-0.99^{2}$ & [21] \\
\hline & 0.94 & [30] & & 0.96 & [22] \\
\hline \multirow{5}{*}{ Inorganic Carbon } & \multirow{5}{*}{0.98} & \multirow{5}{*}{ [30] } & Inorganic Carbon & 0.80 & [34] \\
\hline & & & & $0.84-0.99^{2}$ & [21] \\
\hline & & & & 0.92 & [22] \\
\hline & & & & $0.96^{1}$ & [35] \\
\hline & & & Dolomite & $0.99^{1,2}$ & [36] \\
\hline Total Carbon & 0.95 & [30] & & & \\
\hline \multirow{3}{*}{ Total Nitrogen } & \multirow{3}{*}{$\begin{array}{l}0.76 \\
0.88\end{array}$} & \multirow{3}{*}{$\begin{array}{l}{[29]} \\
{[30]}\end{array}$} & \multirow{3}{*}{ Total Nitrogen } & $0.62-0.84$ & [23] \\
\hline & & & & 0.86 & [34] \\
\hline & & & & 0.99 & [22] \\
\hline Organic Nitrogen & 0.86 & [37] & & & \\
\hline Total Phosphorus & 0.48 & [38] & & & \\
\hline \multirow{3}{*}{$\mathrm{pH}$} & $0.19-0.21$ & [38] & & & \\
\hline & 0.72 & [31] & & & \\
\hline & 0.77 & [29] & & & \\
\hline \multirow{2}{*}{ Electrical Conductivity } & $0.08-0.79$ & [29] & & & \\
\hline & $0.20-0.32$ & [38] & & & \\
\hline Aluminum (dithionate extraction) & 0.69 & [29] & \multirow{2}{*}{ Aluminum Oxide } & \multirow{2}{*}{$0.99^{1,2}$} & \multirow{2}{*}{ [35] } \\
\hline Exchangeable Aluminum & 0.64 & [37] & & & \\
\hline Iron (AAS) & 0.97 & [39] & & & \\
\hline Iron (dithionate extraction) & 0.79 & [29] & & & \\
\hline Iron (DTPA extraction) & 0.55 & [37] & & & \\
\hline \multirow{2}{*}{ Exchangeable Magnesium } & 0.74 & [29] & & & \\
\hline & 0.76 & [37] & & & \\
\hline Lead & 0.66 & [39] & & & \\
\hline \multirow{5}{*}{$\begin{array}{l}\text { Silica (dithionate extraction) } \\
\text { Silica (oxalate extraction) }\end{array}$} & \multirow{5}{*}{$\begin{array}{l}0.69 \\
0.69\end{array}$} & \multirow{5}{*}{$\begin{array}{l}{[29]} \\
{[29]}\end{array}$} & Biogenic Silica & 0.64 & [32] \\
\hline & & & & $0.64-0.94^{2}$ & [21] \\
\hline & & & & 0.93 & [22] \\
\hline & & & & 0.97 & [36] \\
\hline & & & Silicate & $0.98^{1,2}$ & [35] \\
\hline & & & Titanium dioxide & $0.95^{1,2}$ & [35] \\
\hline Zinc & 0.96 & [38] & & & \\
\hline Total Petroleum Hydrocarbons & $0.62-0.92$ & [32] & & & \\
\hline \multirow{3}{*}{$\%$ Clay } & $0.21-0.32$ & [37] & & & \\
\hline & 0.67 & [27] & & & \\
\hline & 0.87 & [30] & & & \\
\hline \multirow{3}{*}{$\%$ Sand } & 0.74 & [27] & & & \\
\hline & $0.79-0.85$ & [28] & & & \\
\hline & 0.94 & [31] & & & \\
\hline & 0.49 & [27] & & & \\
\hline$\%$ Silt & 0.84 & [31] & & & \\
\hline & $0.58-0.79$ & [28] & & & \\
\hline$\%$ Coarse $>2 \mathrm{~mm}$ & $0.33-0.51$ & [37] & & & \\
\hline
\end{tabular}

In comparison to soils, fewer properties of sediments (lacustrine, riverine, or marine) have been quantified using MIRS (Table 1) [22,33-36,40,41]. Furthermore, where MIRS methods have been 
applied to sediments, they have predominantly utilised a mathematical approach [40] whereby the concentration of a compound in a dilute potassium bromide $(\mathrm{KBr})$ disc is linearly related to the absorbance at specific wavelengths. Thus, by knowing the spectral peaks associated with specific compounds and determining the relative height of these, the amounts of compounds present in a sample can be calculated. This approach, along with similar methods based on peak area rather than height, have been used for quantitative determination of silica, carbonate, kaolinite, and other minerals in sediments derived from lake, marine, and riverine environments [42-44]. MIRS has also been used for more detailed investigations, such as identifying humic materials $[45,46]$.

Although spatial calibration models are not widely used for MIRS analysis of sediments (Table 1), there has been some development in this area. For example, predictive models based on MIRS have previously been used to determine the amount of total organic carbon, total inorganic carbon, total organic nitrogen, and biogenic silica within lake sediments [21,23,47]. Such research demonstrates the applicability of MIRS for determining a range of environmental parameters. One advantage of spatial calibration models is that they allow parameters that influence the sediments but do not have a strong spectral signature (within the range being considered) to be inferred. For example, infrared spectroscopy has been used to determine water quality parameters at the time of sediment deposition, such as total organic carbon content [48]. The current paper, therefore, investigates the hypothesis that MIRS can also be used to infer the lake water salinity at the time of sediment deposition.

\section{Materials and Methods}

This study focused on lakes from the western plains of Victoria, Australia (Figure 1) that had a salinity less than $20 \mathrm{mg} \cdot \mathrm{L}^{-1}$. This criterion was implemented because changes in salinity below this point tend to have the greatest ecological impact with regards to turnover of species. Many species that inhabit lakes above this salinity level can tolerate a very wide range of salinity [49], thus changes in salinity will have a proportionally lesser effect. Applying this criterion also enabled us to compare our data with an existing reconstruction [9] derived from a diatom-based calibration model [17]. The latter performs best at lower salinities (presumably because of the greater turnover discussed above), thus using this range would enable an appropriate comparison of the models produced.

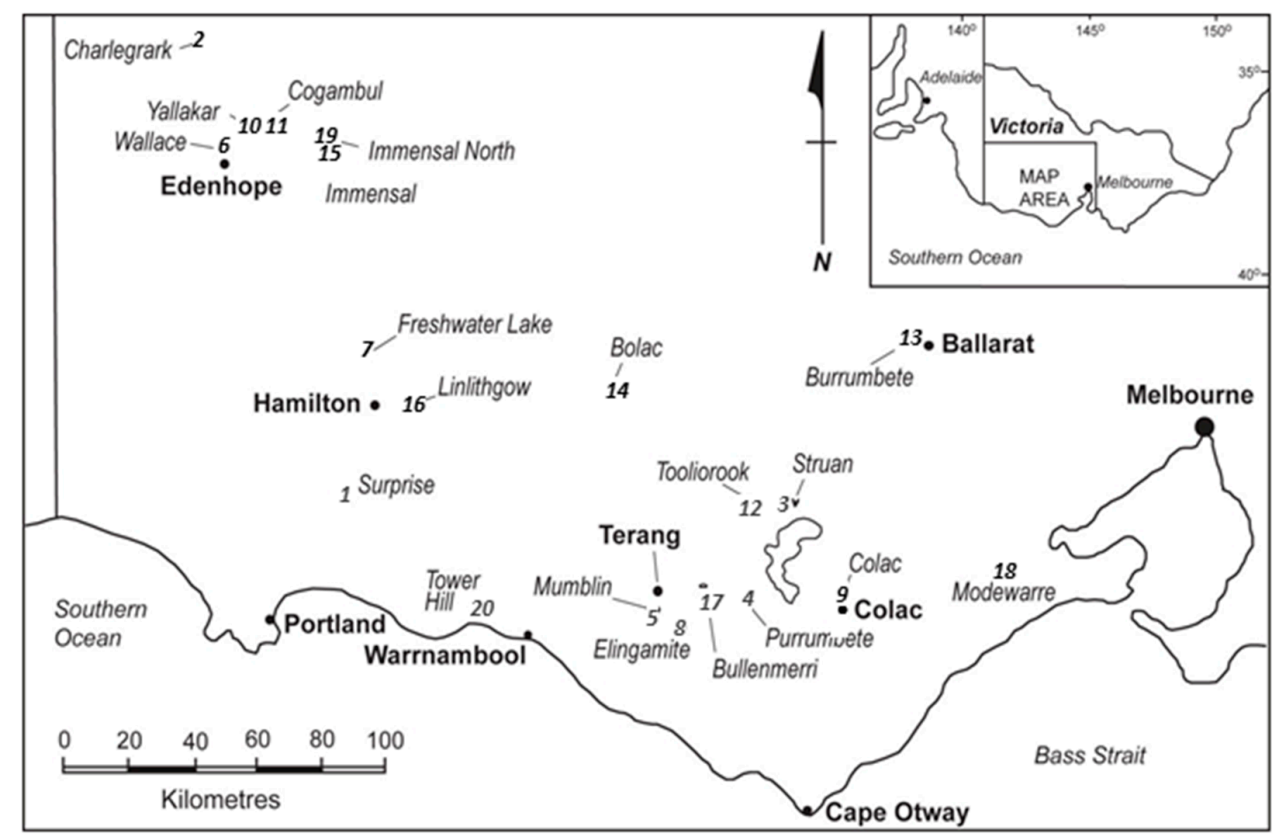

Figure 1. Lakes included in the calibration dataset in order of increasing salinity $(1=$ lowest salinity, $19=$ highest salinity) as well as the site of the salinity reconstruction, Tower Hill Lake (20). 
Based on previously recorded salinities [17], 44 lakes were initially selected for sampling, however, during the field campaign it was found that 15 of these were dry whilst the salinities of 9 others exceeded the selection criterion and 1 lake was inaccessible. Consequently, 19 lakes were incorporated in the calibration dataset. Surface sediments were collected from either the deepest part of the lake or from the centre of the lake when no bathymetric data were available. Sediments were collected using a modified Hongve corer [50]. The sediment/water interface was suctioned off using a large-bore $50 \mathrm{~mL}$ medical syringe; the material removed did not exceed $2 \mathrm{~mm}$ in core depth. This technique was used as the surface sediments were too soft to remove in a more traditional manner (i.e., using a spatula or core cutter). Given the very rapid sedimentation rates observed in almost all Australian lakes since European arrival [51-54] and the thin layer of sediment collected, it is assumed that the samples represent a few years of accumulation, at most.

Electrical conductivity (EC), as an indicator of salinity, was measured at the time of sediment sampling using a TPS 90-FL Field Lab multimeter that was calibrated before each use. EC measurements were taken from within the photic zone, approximately $1 \mathrm{~m}$ below the water surface. The salinity was calculated by multiplying the measured EC value by 0.64 [55]. Water temperature, $\mathrm{pH}$, and dissolved oxygen (DO) were also measured in the field using this device. As the majority of these lakes are shallow ( $<5 \mathrm{~m}$ deep), minimal stratification is assumed and thus no attempt was made to measure changes in these parameters with depth through the water column. Water samples were collected approximately $50 \mathrm{~cm}$ below the surface for the analysis of chloride $(\mathrm{Cl})$, alkalinity, aluminium $(\mathrm{Al})$, iron $(\mathrm{Fe})$, calcium $(\mathrm{Ca})$, potassium $(\mathrm{K})$, magnesium $(\mathrm{Mg})$, sodium $(\mathrm{Na})$, total nitrogen (TN), total phosphorus (TP), and sulphur (S). Water samples were also collected and filtered to allow the dissolved concentrations of the latter 7 parameters to be determined, along with phosphate and total carbon (TC). Analyses of these samples were undertaken at the Commonwealth Scientific and Industrial Research Organisation (CSIRO) Land and Water laboratories using standard methods. This range of chemical data was intended to provide information about the calibration lakes and their settings with only a subset consisting of $\mathrm{Cl}, \mathrm{Ca}$, dissolved $\mathrm{N}, \mathrm{EC}$, and $\mathrm{pH}$ incorporated in the calibration dataset. These parameters are all ecologically meaningful yet, despite previous research indicating that MIRS-based models can quantify these parameters within soils [29,31], these methods have yet to be applied to lake sediments. In contrast, well-developed MIRS-based calibration models already exist for quantifying the proportion of organic carbon, inorganic carbon, and biogenic silica in lake sediments; thus these compounds were not considered here.

An existing sediment core from Tower Hill forms the basis of the salinity reconstruction developed herein. This core was collected in 2000 with both collection and subsampling details described elsewhere [9]. To briefly summarise, two cores were collected approximately $50 \mathrm{~m}$ in from the western edge of the lake. One of these was predominantly used for dating and midge studies whilst the second core was primarily used for the diatom reconstruction; remnant samples from the latter have been used herein. The chronology consisted of $10^{210} \mathrm{~Pb}$ dates constrained by a marked change in stratigraphy that corresponded to the date the lake was most recently inundated [9]. Sediments below this stratigraphic marker could not be reliably dated using ${ }^{210} \mathrm{~Pb}$ and thus have not been included within this study.

Prior to MIRS analyses, samples were air-dried and machine-ground to a fine powder (nominal particle size of $<100 \mu \mathrm{m}$ ) in a single puck $\operatorname{Rocklabs}^{\odot}$ mill. Samples were analysed as neat powders using a rapid scanning Fourier-transform spectrometer (Bio-rad 175C, Hercules, CA, USA) with an extended range $\mathrm{KBr}$ beamsplitter and DTGS (deuterated triglycine sulphate) detector (spectral range of $8300-440 \mathrm{~cm}^{-1}$ ) at $4 \mathrm{~cm}^{-1}$ resolution. Spectral frequencies were referenced against an internal $\mathrm{He}-\mathrm{Ne}$ laser to give a precision and accuracy of $0.01 \mathrm{~cm}^{-1}$. The diffuse reflectance accessory (Harrick ${ }^{\mathrm{TM}}$ DRS-3SO) used off-axis geometry and was set up for maximum energy without removing stray specular radiation. An initial $\mathrm{KBr}$ blank spectrum was run to test the spectrometer performance and as a reference for calculating the sample spectra in absorbance units. Each sample spectrum acquisition and processing took $1 \mathrm{~min}$ per sample over 60 scans. Only the MIRS range $\left(4000-470 \mathrm{~cm}^{-1}\right)$ was used for further analysis. Spectra were baseline corrected prior to model development. All data 
were mean centred and chemical data were autoscaled in The Unscrambler V 9.8 (Camo Software AS, Oslo, Norway). Chemical parameters were then related to the spectral dataset using the kernel partial least-squares (PLS) regression model available in The Unscrambler. A PLS analysis was performed in the Unscrambler for each variable, individually, using the autofit function. This function fits the number of axes that the software thinks best explains the variance in the data. The plots of residual variance were used to confirm the optimal number of axes. Models were initially developed using untransformed chemical data, however, given the skewed distribution observed for some variables, a square-root transformation was also applied. Cross-validation of PLS models was performed using an iterative, leave-one-out, procedure (LOOCV). In the latter, one lake is omitted from the calibration model, the salinity is predicted for that lake and then compared to the actual measured value. The model is then re-run including the first lake that was omitted but with a second lake left out. This process continues until each lake has been sequentially omitted. This provides an estimate of the error associated with the model. The above analyses were all performed using The Unscrambler V 9.8 (Camo Software AS).

An independent validation was performed to assess the validity of salinity values inferred from the MIRS calibration model. Reconstructed values from a sediment core collected from Tower Hill Lake in 2000 were compared to historical monitoring data. Salinity data were available for 1983-1990 from the Tower Hill Lake State Game Reserve, from two sampling locations. EC data were available for 1993-1996 from Australian Water Technologies. To facilitate comparisons between the different datasets, EC was again converted to salinity using a conversion factor of 0.64 [55]. Due to irregular sampling frequencies, annual averages have been calculated from these datasets. In addition, a single salinity measurement was also available for 2007 and 2008 [56]. Finally, the MIR-inferred salinity reconstruction was compared with a diatom-inferred salinity record from this site [9]. Errors on the two different reconstructions have been calculated as \pm the root mean squared error (RMSE) of the model.

\section{Results}

The calibration lakes were all well-oxygenated and predominantly circumneutral to slightly alkaline (Table 2). The majority of lakes had a water depth less than $5 \mathrm{~m}$ and water temperatures within the upper meter ranged between 17 and $23{ }^{\circ} \mathrm{C}$ (Table 2). Nutrient levels were frequently low, although a few lakes within the calibration set had higher nutrient levels (Figure 2). Although the criterion used to select the lakes was that the salinity was less than $20 \%$, the highest recorded salinity within the calibration dataset was $10.2 \%$. Temperature, $\mathrm{pH}, \mathrm{EC}, \mathrm{Cl}$, and $\mathrm{Na}$ all showed a relatively even distribution across their gradients (Figure 2). Although DO had a relatively even distribution, there were a few outliers with higher values. The remaining variables were all skewed to varying degrees, with more samples in the low-mid values and fewer samples with higher values (Figure 2). A pronounced outlier was visible in each of TN, P, and S (Figure 2); the outlying sample for TN and TP was from Yallakar Lake whilst the outlying $S$ sample was from Immensal North. EC was strongly correlated with $\mathrm{Na}$ and $\mathrm{Cl}(\mathrm{R}=0.94$ and 0.89 , respectively). EC showed moderate correlations $(\mathrm{R}=0.47$ and 0.53$)$ with $\mathrm{K}$ and $\mathrm{Mg}$, respectively, but no correlation with $\mathrm{Al}, \mathrm{Ca}$, or TP. A weak negative correlation $(\mathrm{R}=-0.3)$ was observed between EC and alkalinity. These results reinforce previous findings that $\mathrm{Na}$ and $\mathrm{Cl}$ are the dominant salts present in surface waters from this area [57] and justify the use of EC as a measure of salinity within this study [55].

Significant variability was observed in the spectra of the different sediment samples (Figure 3), especially within the lower spectral range, which suggests varying mineralogy or organic content. However, of the chemical parameters examined, only salinity showed a significant relationship with the spectral data. No significant axes were identified for any parameter other than $\mathrm{EC}$ and $\sqrt{ } \mathrm{EC}$, and thus $\mathrm{R}^{2}$ values could not be calculated for the other variables. It is noted, however, that only a small number of chemical parameters were assessed and these results do not preclude other environmental or chemical variables from also influencing the spectra. The results do, however, indicate that the salinity 
at the time of sediment deposition exerts some influence on the spectral signature of lake sediments. Interestingly, as the salinities increase, the spectral differences between samples diminish, thus less variability is observed between the spectra of lakes 16-19 than is seen between lakes 1-5 (Figure 3). A biplot of the PLS components (Figure 4A) shows samples with salinity less than 2.5\% (lakes 1-8) form a separate group to those with higher salinities. This separation indicates that the spectral signature of the sediments reflects, to some degree, the salinity of lake water overlying the sediments at the time of their deposition. The lakes with low salinities tend to be more widely dispersed on the scatter plot (Figure 4A) than lakes of higher salinities, again reflecting the greater variability observed in the spectra of the former (Figure 3).
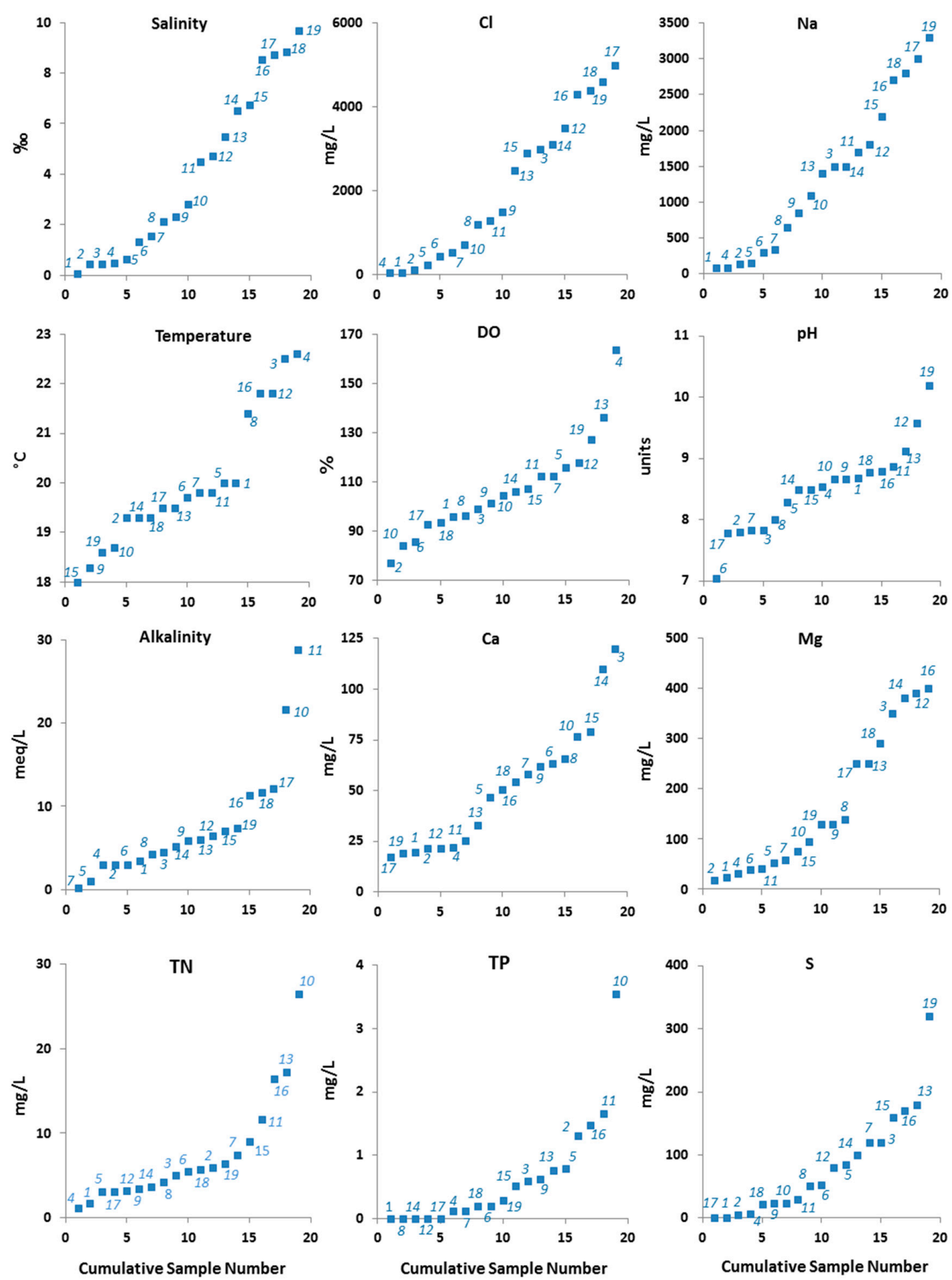

Figure 2. The distribution of physical and chemical data from lakes included within this study. Each parameter has been arranged in order of increasing values for that parameter; lake names and locations are shown in Figure 1. 
Table 2. Summary statistics for physical and chemical parameters of lakes within the calibration dataset. Data presented is from the unfiltered water samples, thus represents both dissolved and particulate matter.

\begin{tabular}{cccccc}
\hline Parameters & Minimum & Maximum & Mean & Standard Deviation & Skewness \\
\hline Salinity (\%) & 0.5 & 10.2 & 4.2 & 3.5 & 0.5 \\
EC $(\boldsymbol{\mu S} / \mathbf{c m})$ & 0.7 & 15.9 & 6.6 & 5.4 & 0.5 \\
DO (\%) & 77.1 & 163.4 & 106.6 & 20.1 & 1.2 \\
pH (pH units) & 7.0 & 10.2 & 8.5 & 0.7 & 0.4 \\
Temperature ( $\left.{ }^{\circ} \mathbf{C}\right)$ & 18.0 & 22.6 & 20.0 & 1.4 & 0.7 \\
Alkalinity $(\mathbf{m e q} / \mathbf{L})$ & 0.2 & 28.8 & 7.7 & 7.1 & 1.9 \\
Cl $(\mathbf{m g} / \mathbf{L})$ & 45.1 & 5000.0 & 2076.1 & 1733.6 & 0.3 \\
TN $(\mathbf{m g} / \mathbf{L})$ & 1.1 & 26.5 & 7.4 & 6.4 & 1.8 \\
Al (mg/L) & 0.0 & 400.0 & 36.0 & 92.6 & 3.8 \\
Fe (mg/L) & 0.0 & 290.0 & 26.0 & 67.0 & 3.8 \\
Ca (mg/L) & 17.4 & 120.0 & 50.9 & 30.7 & 0.8 \\
K (mg/L) & 5.5 & 140.0 & 48.0 & 40.9 & 0.2 \\
Mg (mg/L) & 18.5 & 400.0 & 165.6 & 138.7 & 0.4 \\
Na (mg/L) & 85.0 & 3300.0 & 1347.8 & 1068.6 & 2.3 \\
TP(mg/L) & 0.0 & 3.5 & 0.6 & 0.9 & 1.4 \\
S (mg/L) & 1.1 & 320.0 & 81.6 & 82.7 &
\end{tabular}

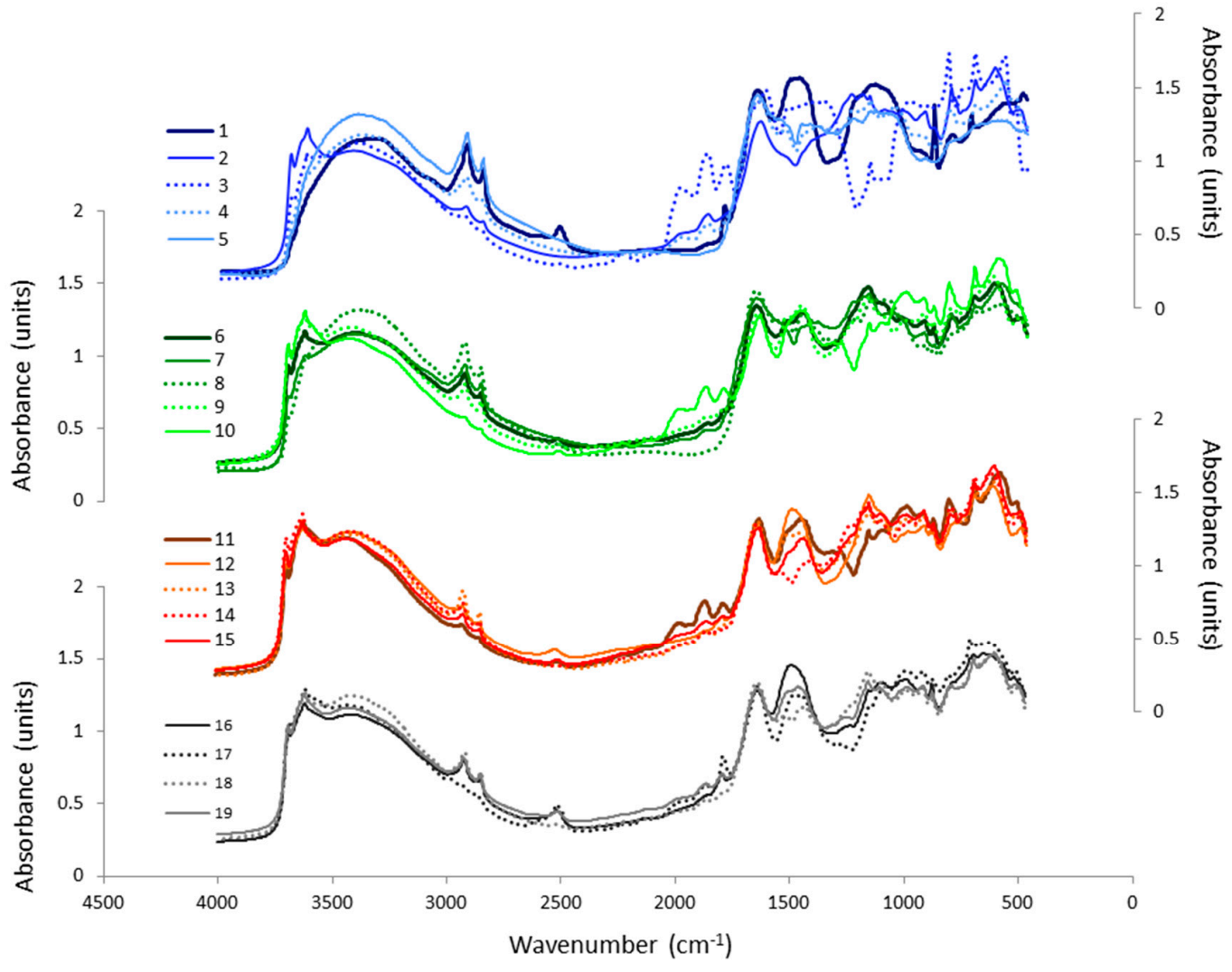

Figure 3. MIRS spectra of lakes used in the calibration dataset, in order of increasing salinity. See Figure 1 for lake location or Table 2 for physical and chemical data.

A plot of the residual variance indicates the initial amount of variance within the dataset, the amount remaining after each component is sequentially added to the model, and the amount of variance that is explained by each component (Figure 4B). In this plot, the "calibration" set refers to a model which incorporates all 19 lakes and thus shows the fit of the model to the training data. In contrast, the validation data is derived from the iterative LOOCV procedure and thus provides an indication of the prediction error of the model variation (Figure 4B). For example, the calibration 
data suggest that a five-component model would account for $90 \%$ of the variance within the dataset, with a nine-component model accounting for $99 \%$ of the variance. In contrast, the validation data shows that a five-component model explains only $\sim 65 \%$ of the variance. Furthermore, within the validation data, $19 \%$ of the variance cannot be explained regardless of how many additional components are included. This indicates that some of the explained variance within the calibration set is not related to salinity but rather is attributable to other differences in the spectra. This raises the possibility that another variable, not captured within the calibration dataset, contributes to the spectral variability. This could potentially relate to the variability observed within samples from lakes with low salinity values discussed above. However, the high residual variance could also indicate a significant component of noise within the model, which could result from the small number of lakes incorporated within the calibration dataset.

The residual variance should decrease as additional components are added to the model. If the residual variance remains the same, it indicates that the additional component is reflecting variance that has already been captured by one or more of the existing components. If the variance increases with the addition a component, this indicates that variable represents a component associated with noise in the calibration dataset. Consequently, the slight increase in residual variance observed within the validation data for a six-component model can be attributed to noise and thus indicates that a five-component model is the best choice for these data. A five-component PLS model for $\sqrt{ } \mathrm{EC}$, as a measure of salinity, was subsequently developed and performed reasonably $\left(R^{2}\right.$ LOOCV $=0.64$, RMSEP $\left.=0.7 \mathrm{~g} \cdot \mathrm{L}^{-1}\right)$. It is noted, however, that the model underestimates the variance within the calibration set, with values in the lower range overestimated and values in the upper range underestimated (Figure 4C).
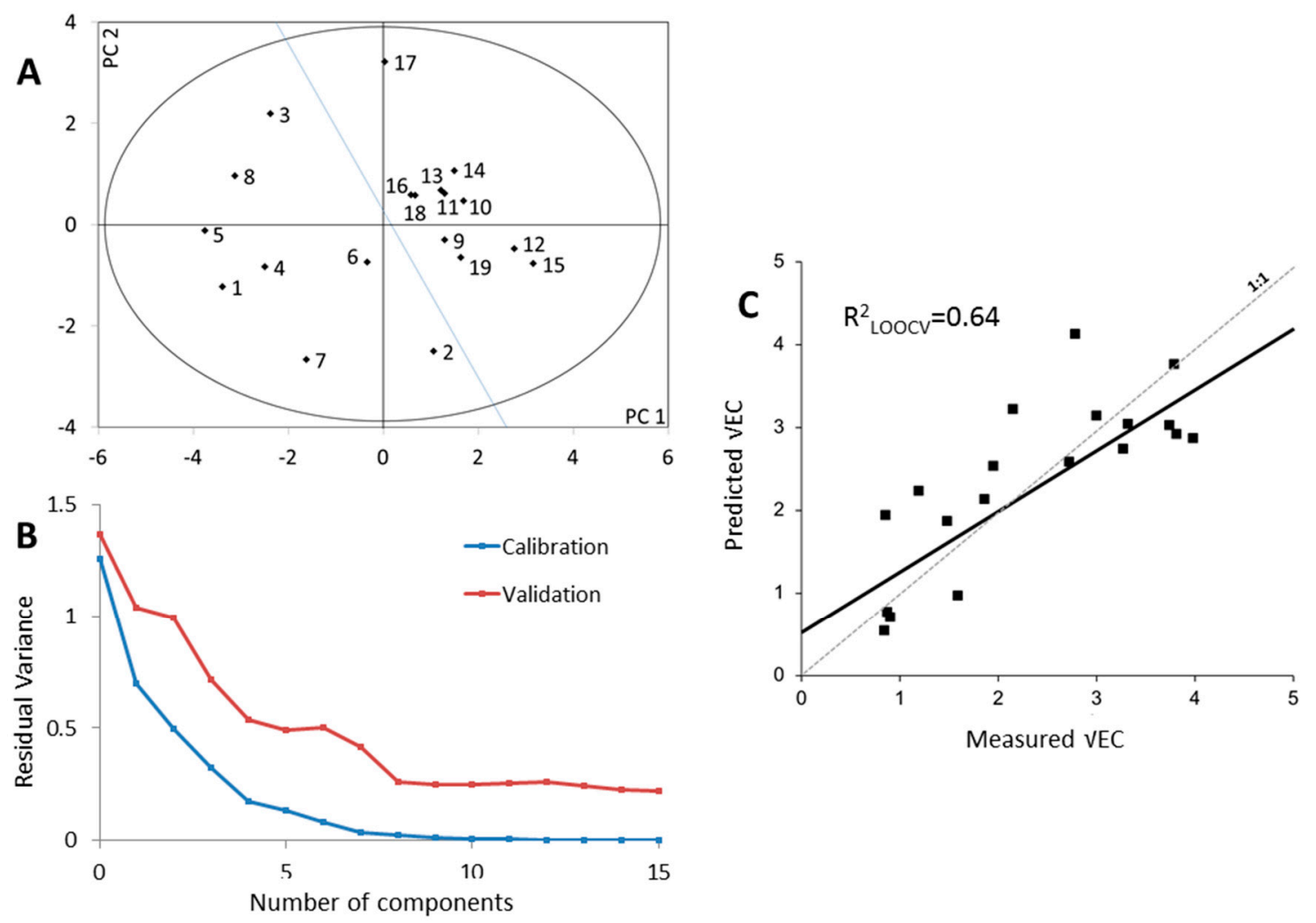

Figure 4. (A) A biplot of the PLS components showing the distribution of lakes (numbered in order of increasing salinity) with lakes of salinities $<2.5 \%$ located to the left of the grey line; (B) the residual variance with differing numbers of model components and (C) a comparison of MIRS predicted conductivity values $(\sqrt{ } \mathrm{EC})$ with measured values, using an iterative, leave-one-out cross-validation process, and with the regression line shown (-). 
The first two components (PC1 and PC2) have 43\% and 29\% influence on the model, respectively (Figure 4B). Further components have less effect on the model. The influence of the spectral regions on each component in the salinity model is indicated by the loading weights. Although the full spectral range used is shown, wavelengths associated with higher loading weights will have the greatest influence on the model, whilst those with smaller loadings will have less influence. The loading plot (Figure 5) shows that the relationship between PC1 and salinity is predominantly influenced by kaolinite, signified by the three peaks between 3600 and $3700 \mathrm{~cm}^{-1}[40,58]$. The peak at $918 \mathrm{~cm}^{-1} \mathrm{may}^{-1}$ also indicate an influence of kaolinite on PC1, but this peak is not definitive. Many compounds with bonds visible within the lower wavenumbers have spectra that overlap, and the resulting complexity of the spectra can hinder identification. PC1 is also negatively related to organic matter (OM), as indicated by the alkyl peaks around $2800-2900 \mathrm{~cm}^{-1}$ [40].

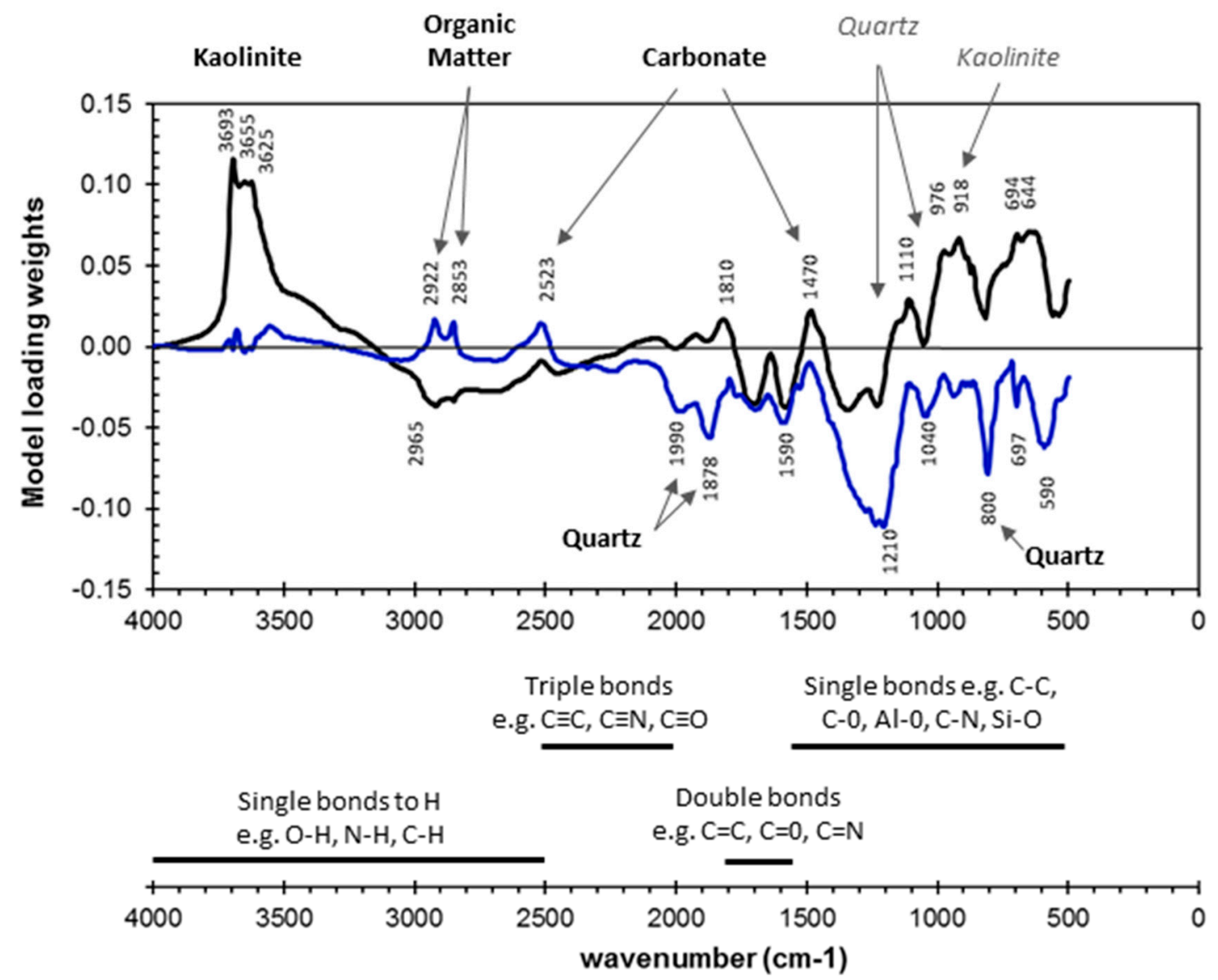

Figure 5. Loading plot showing the relative importance of individual wavenumbers to the first two PC axes of the salinity inference model. Wavenumbers with higher values (either positive or negative) contribute more to the model. Peak numbers are provided for peaks to help identify compounds that are likely to be influencing the model. Spectral characteristics that are definitive or potentially indicative of various compounds are labelled accordingly. Chemical bonds typically associated with the varying wavenumbers are also shown.

As the $\mathrm{CH}_{3}$ stretching vibrations at $2965 \mathrm{~cm}^{-1}$ are of a similar magnitude to the $\mathrm{CH}_{2}$ vibrations at 2853 and $2922 \mathrm{~cm}^{-1}$, the OM seen as a negative correlation in PC1 probably represents a range of organic materials with short alkyl chain lengths. A small band at $3060 \mathrm{~cm}^{-1}$ is characteristic of $\mathrm{C}=\mathrm{C}-\mathrm{H}$ stretching and is seen in spectra of humic materials. Weak, positive relationships are observed between PC2 and organic carbon, particularly C-H bonds shown by the peaks at 2850 and $2950 \mathrm{~cm}^{-1}[40,44,59]$. In contrast to PC1, the stronger, positive peaks for $\mathrm{CH}_{2}$ vibrations at 2853 and $2922 \mathrm{~cm}^{-1}$ in $\mathrm{PC} 2$ 
suggests that longer chained materials, such as lipids, are responsible. Although quartz peaks around $800,1040,1878$, and $1990 \mathrm{~cm}^{-1}[40,44,59]$ are negatively related to both PCs, they exert a much stronger influence on PC2 (Figure 5). Three small carbonate peaks are observed on the loading plot at 1470, 1810 , and $2523 \mathrm{~cm}^{-1}[22,31,36]$, influencing both PC1 and PC2.

Given the significant relationship between MIRS-predicted and measured salinity in the spatial calibration model, the model was applied to down-core samples from Tower Hill Lake. The resulting MIRS-inferred salinity reconstruction (Figure 6) indicates that a sharp decrease in inferred salinity values occurred between 1946 and 1955. This decrease was followed by a gradual, long-term increasing trend that persisted until the late 1980s. Subsequent to this, the MIRS-inferred salinity levels fluctuated from $5 \%$ to $6 \%$ but exhibited a greater degree of variability between samples than had previously been observed. The MIRS-inferred values are within the lower range of salinity measured between 1983 and 1990 (Figure 6). However, the salinity data collected in the 1980s show a higher degree of variability than that seen within the MIRS reconstruction, with the annual averages varying between $5.4 \%$ and $12.3 \%$. In contrast, the MIRS inferred values agree relatively well with salinity measurements reported in the 1990s, where the annual averages ranged between $4.3 \%$ and $7.0 \%$. Climatic changes could explain the differences in variance observed, however, part of these observed differences are likely to be associated with the higher frequency of sampling during the 1980s as this would result in a greater range of values being captured, as well as increasing the potential for extreme values to be recorded.

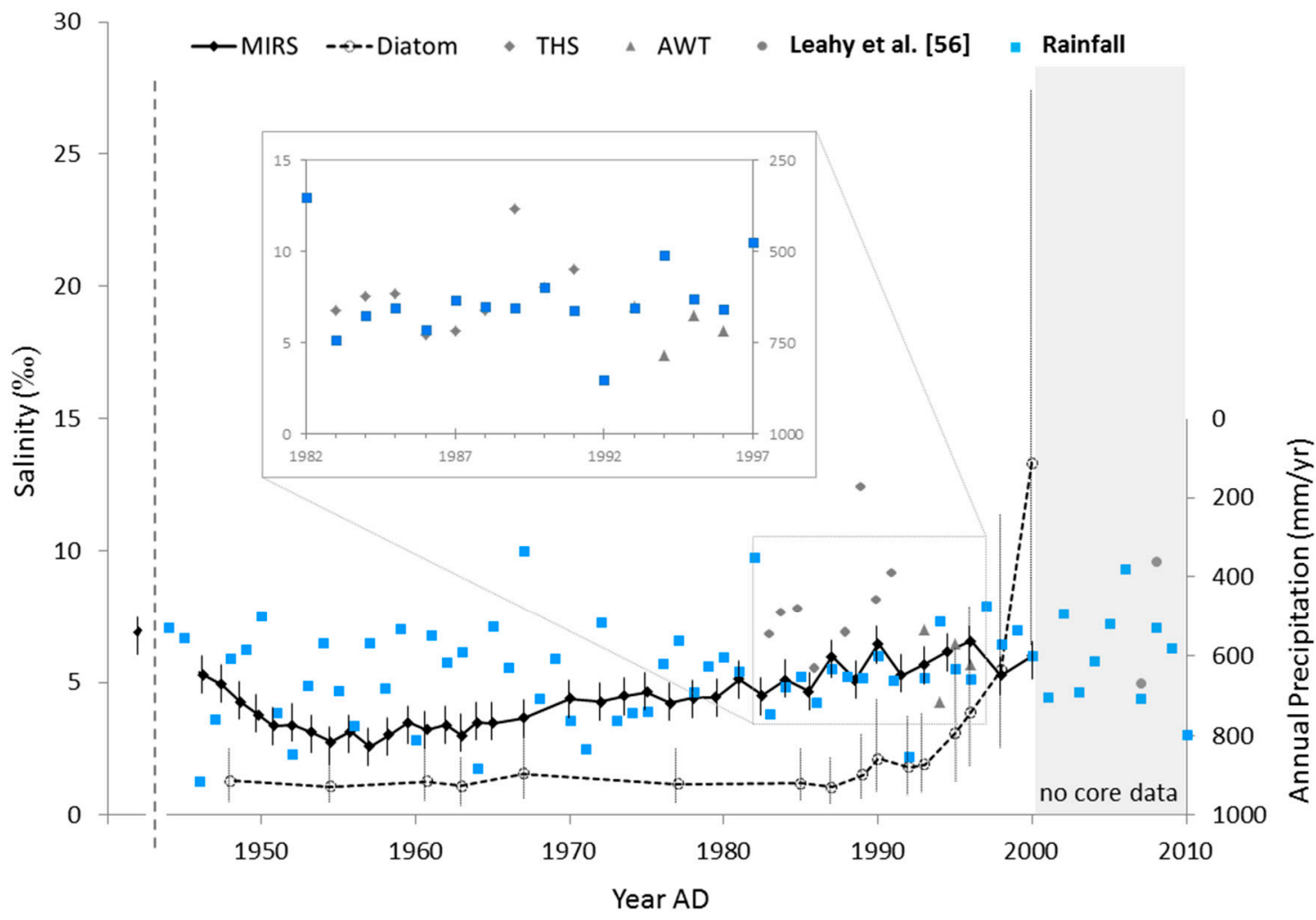

Figure 6. Comparison of MIRS inferred salinity values $(\bullet)$ for Tower Hill Lake with both diatom-inferred (०) salinity, salinity measurements undertaken by various bodies (grey symbols), in conjunction with the annual rainfall (๘) for the Tower Hill grid square (scale inverted; data from the Australian Bureau of Meteorology). The inset highlights the relationship between the average annual salinity measurements and annual precipitation (note that different scales are used for the axes).

The diatom-inferred values showed little resemblance to the MIRS-inferred values throughout most of the core, although detailed comparisons are difficult given the lower sample frequency seen in the diatom reconstructions. Prior to 1990s, the diatom model shows little variation whereas the 
MIRS-inferred values suggest an initial decline followed by a generally increasing trend up-core. After 1990, the diatom-inferred values show some initial variability followed by an almost exponential increase in salinity between 1995 and 2000. In contrast, the MIRS model suggests a period of relatively stability occurred between 1990 and 2000, with fluctuations varying between 5\% and 6\%. Thus, there is a cross-over period between when the diatom model indicates lower salinity values than the MIRS model, and when the diatom model shows higher variability than the MIRS model. There is also a significant increase in error associated with diatom-inferred values above $3 \%$ and thus there is a slight overlap between the two models from 1955 to 1970 and 1995 to 1998 when the associated errors are included (Figure 6). The diatom-inferred salinity values are much lower than the measured values during the 13 years for which the latter data is available. There is no overlap between any of the measured values and the inferred salinity values, even when the error range of the diatom model is considered. Finally, the highest diatom-inferred salinity values during the period for which monitoring data is available, correspond to some of the lowest salinity values observed within the monitoring data.

\section{Discussion}

This study demonstrates the potential to use MIRS to reconstruct lake salinity in Australia, and potentially around the world. The inference model's ability to infer salinity is predominantly linked to changes in the mineralogy of the sediments with changes in the organic content also contributing a small component. These results agree well with MIRS studies of Australian soils, where inference models for EC were strongly influenced by kaolinite, smectite, gibbsite, and quartz [31]. Hence, we would caution that this initial model is reflective of the environmental and geological conditions found within the study region. As such, the model itself should not be applied to areas outside of this region; however, the technique of using MIRS to develop a calibration model and subsequently infer past salinity could be applied elsewhere. Similarly, the model presented here is only suitable for lakes with a low salinity; it should not be assumed that the model can be extrapolated beyond the range of salinities observed. Further research is required to determine whether higher salinities can be inferred using MIRS, and if so, whether the relationships with mineralogy observed here are still maintained for lakes with higher salinities.

Within the model presented here, the relationships observed between sediment composition and salinity probably reflect a combination of weathering and depositional influences, with a minor contribution from in-lake processes. For example, clay minerals are common weathering products that generally do not require intense chemical weathering and can therefore be formed by physical weathering during low rainfall dry phases [60,61]. In contrast, a high degree of chemical weathering, typically associated with intense leaching and high rainfall, is required to produce silica from mafic igneous rocks [60], such as those found in the study area. Furthermore, high stream flow is generally required for aqueous transport of quartz into lake sediments, whereas lighter clay minerals are more easily transported by lower streamflow. Thus, high levels of quartz are likely to indicate high precipitation that, in turn, would be likely to lower the salinity levels of lakes within the affected area. It is possible for both clay minerals and quartz to be transported into lakes by wind, although as is the case for stream flow, less energy is required to transport clay minerals. This could also contribute to the observation that high salinity values were associated with a greater amount of clay minerals. For example, if in dry conditions, clay minerals from soils were preferentially transported by wind [62], this would increase the amount of clay minerals present within the lake sediments. Thus, differences in the weight of minerals and preferential transport by either wind or water could act in conjunction with different weathering regimes to produce the observed relationships between the mineral composition of lake sediments and the salinity present at the time of sediment deposition.

Despite the predictive power of the MIRS salinity model, the reconstruction from the Tower Hill Lake sediments did not fully capture the variability observed within the measured values (Figure 5). This is probably attributable to the smoothing influence of sedimentary processes in lakes, 
including sediment mixing. Given that a number of the properties inferred from MIRS are related to increased rates of weathering and delivery of materials from lake catchments, it may be that the model is less well suited to inferring subdecadal changes in lake salinity. However, this is a characteristic of most lake-based salinity reconstructions, as other biological proxies are also often affected by catchment processes. These processes can affect variables such as light availability, nutrient supply, or $\mathrm{pH}$ and thus subsequently influence the community composition of a range of proxies. As an example, the diatom reconstruction used herein captured even less of the variability in the monitoring data.

The MIRS-inferred reconstruction shows some trends that broadly correspond to regional rainfall. During the first half of the 20th century, the southwest region of Victoria experienced approximately 50 years of relatively low precipitation, with the eastern side of Tower Hill Lake drying out in 1942 [9]. This was followed by a very wet period commencing in the 1950s [56] that led to flooding of several lakes, including Lake Corangamite and Lake Colac. This timing correlates well with the decrease in salinity observed between 1946 and 1955 in the MIRS reconstruction. The long-term increase in salinity values is consistent with a long-term decrease in precipitation. Despite this, the MIRS-inferred values do not reflect the quasi-decadal variability seen within the precipitation records (Figure 6). From the 1980s on, the rainfall shows less variability and more coherence is apparent between the MIRS-inferred salinity reconstruction and the historic rainfall data from this point on.

The diatom-based salinity reconstruction shows little variation before 1990, with inferred values ranging between $1.0 \%$ and $1.6 \%$ (Figure 6). During the next five years, inferred values are slightly higher $(\sim 2 \%)$, however, it is not until $\sim 1996$ that values increase markedly with the three uppermost samples rising sharply. This marked increase in diatom-inferred salinity levels during the latter part of the 1990s corresponds to lower-than-average precipitation, including a drought in 1997 [63]. Unfortunately, no measured salinity data are available for 1995-2000, thus the latter relationship cannot be verified. It is worth noting, in the 2007-2008 austral summer, after 12 years of prolonged drought within the region (including pronounced drought conditions during 2002, 2006, and 2008) [63], measured salinity values within Tower Hill Lake varied between $5.0 \%$ in November and $9.6 \%$ in April [56]. Consequently, the high salinity level indicated by the diatom-inferred reconstruction for the late 1990s appears unrealistic.

Given the lack of agreement throughout the record between the measured salinity data and the diatom-inferred reconstructions, MIRS should be considered as an alternative method for reconstructing past salinity levels in Australian lakes. Whilst the MIRS reconstruction does not capture variability on the subdecadal scale, it reflects the long-term trends and infers values that more accurately reflect the measured data. Consideration should, therefore, be given to expanding the number of lakes incorporated within the model to improve the reliability and statistical performance as well as expanding the range of lake water salinities covered.

Finally, it is noted that the diatom model is intended to capture a biological response to salinity while the MIRS calibration model appears to be more related to catchment process (weathering and erosion) than in-lake conditions. One implication of this is that the MIRS model is primarily responding to climatic changes on a local, or possibly regional, scale rather than salinity per se. Consequently, MIRS calibration models may potentially provide information pertaining to drought history as indicated by the mineralogy. Although similar information may be obtained through more traditional chemical analyses or X-ray fluorescence, MIRS offers a cheaper, faster alternative to these methods [35,36]. As such, it represents an intriguing possibility for a cost-effective means for examining past climatic change in an area that is predicted to become more prone to drought in the future. Given that recent increases in salinity have been observed in many waterbodies within Australia, this method could also prove an invaluable tool for ongoing management of these water bodies; for example, by providing the baseline data required to set realistic targets for remediation work. 


\section{Conclusions}

This study demonstrates the feasibility of using MIRS for reconstructing lake salinity. However, the number of lakes used in this study is small, with all lakes located in the same geographical region. Consequently, additional region-specific calibration models would need to be developed before the method could be applied elsewhere. Further research would also be required to develop a salinity model that is applicable for lakes with higher salinity values. Despite this caveat, our study indicates that MIRS could be a valuable technique for reconstructing lake salinity (including drought history) in south-eastern Australia.

Acknowledgments: Funds for the open access publishing were provided by the Faculty of Science, University of Portsmouth. Funds for the collection and analysis of surface sediment samples were provided by The Faculty of Humanities and Social Sciences, University of Adelaide. The Tower Hill Lake study was supported Monash University Arts Faculty Small Grant and a Victoria University of Technology small grant. Simon Haberle and David Tooth assisted core collection. Agnieszka Lonska (Australian Water Technologies) provided water quality data for the period 1993-1996. Peter Coverdale (then ranger at Tower Hill Lake State Game Reserve) gave permission for, and facilitated, the use of salinity measurements for the period 1983-1990. Annual rainfall anomaly data were obtained from the Bureau of Meteorology: (http://www.bom.gov.au/cgi-bin/climate/ change/timeseries.cgi). Finally, we would like to acknowledge the two anonymous reviewers, whose detailed input was greatly appreciated and which substantially improved this paper.

Author Contributions: John Tibby, Cameron Barr and Jan Skjemstad conceived the idea and designed the study. Cameron Barr undertook the field sampling. John Tibby developed the diatom-based salinity reconstruction, obtained the historical salinity data and undertook initial comparisons to meteorological records. Sean Forrester performed the spectral analysis and developed the MIRS model. Laura Cunningham interpreted the results and undertook comparisons between the two inference models, historical salinity measurements and the climate data. Laura Cunningham wrote the bulk of the paper with input from John Tibby, Sean Forrester, Cameron Barr and Jan Skjemstad.

Conflicts of Interest: The authors declare no conflict of interest.

\section{References}

1. Australian Bureau of Statistics (ABS). Measures of Australia's Progress, 2010; ABS: Canberra, Australia, 2010; p. 223.

2. National Land and Water Resources Audit (NLWRA). Australian Dryland Salinity Assessment 2000; NLWRA: Canberra, Australia, 2001; p. 129.

3. Gell, P.; Fritz, S.; Battarbee, R.; Tibby, J. LIMPACS-Human and Climate Interactions with Lake Ecosystems: Setting research priorities in the study of the impact of salinisation and climate change on lakes, 2005-2010. Hydrobiologia 2007, 591, 99-101. [CrossRef]

4. Nielsen, D.L.; Brock, M.A.; Rees, G.N.; Baldwin, D.S. Effects of increasing salinity on freshwater ecosystems in Australia. Aust. J. Bot. 2003, 51, 655-665. [CrossRef]

5. Australian and New Zealand Environment and Conservation Council (ANZECC). Implications of Salinity for Biodiversity Conservation and Management; Task Force for the Standing Committee on Conservation: Canberra, Australia, 2001; p. 59.

6. Gell, P. With the benefit of hindsight: The utility of palaeoecology in wetland condition assessment and identification of restoration targets. In Ecology of Industrial Pollution (Ecological Review Series); Batty, L., Hallberg, K., Eds.; Cambridge University Press \& the British Ecological Society: Cambridge, UK, 2010; pp. 162-188.

7. Pearson, S.; Lynch, A.J.J.; Plant, R.; Cork, S.; Taffs, K.; Dodson, J.; Maynard, S.; Gergis, J.; Gell, P.; Thackway, R.; et al. Increasing the understanding and use of natural archives of ecosystem services, resilience and thresholds to improve policy, science and practice. Holocene 2015, 25, 366-378. [CrossRef]

8. Juggins, S. Quantitative reconstructions in palaeolimnology: New paradigm or sick science? Quat. Sci. Rev. 2013, 64, 20-32. [CrossRef]

9. Barry, M.J.; Tibby, J.; Tsitsilas, A.; Mason, B.; Kershaw, P.; Heijnis, H. A long term lake salinity record and its relationship to Daphnia populations. Arch. Hydrobiol. 2005, 163, 1-23. [CrossRef]

10. Gell, P.; Tibby, J.; Little, F.; Baldwin, D.; Hancock, G. The impact of regulation and salinisation on floodplain lakes: The lower River Murray, Australia. Hydrobiologia 2007, 591, 135-146. [CrossRef] 
11. Kemp, J.; Radke, L.C.; Olley, J.; Juggins, S.; De Deckker, P. Holocene lake salinity changes in the Wimmera, southeastern Australia, provide evidence for millennial-scale climate variability. Quat. Res. 2012, 77, 65-76. [CrossRef]

12. Gouramanis, C.; Wilkins, D.; De Deckker, P. 6000 years of environmental changes recorded in Blue Lake, South Australia, based on ostracod ecology and valve chemistry. Palaeogeogr. Palaeoclim. Palaeoecol. 2010, 297, 223-237. [CrossRef]

13. Gouramanis, C.; Dodson, J.R.; Wilkins, D.; De Deckker, P.; Chase, B.M. Holocene palaeoclimate and sea level fluctuation recorded from the coastal Barker Swamp, Rottnest Island, south-western Western Australia. Quat. Sci. Rev. 2012, 54, 40-57. [CrossRef]

14. Haynes, D.; Skinner, R.; Tibby, J.; Cann, J.; Fluin, J. Diatom and foraminifera relationships to water quality in The Coorong, South Australia, and the development of a diatom-based salinity transfer function. J. Paleolimnol. 2011, 46, 543-560. [CrossRef]

15. Barr, C.; Tibby, J.; Gell, P.; Tyler, J.; Zawadzki, A.; Jacobsen, G.E. Climate variability in south-eastern Australia over the last 1500 years inferred from the high-resolution diatom records of two crater lakes. Quat. Sci. Rev. 2014, 95, 115-131. [CrossRef]

16. Tibby, J.; Kershaw, A.P.; Builth, H.; Philibert, A.; White, C. Environmental change and variability in south-western Victoria: Changing constraints and opportunities for occupation and land use. In The Social Archaeology of Australian Indigenous Societies; David, B., Barker, B., McNiven, I., Eds.; Aboriginal Studies Press: Canberra, Australia, 2006; pp. 254-269.

17. Gell, P.A. The development of diatom database for inferring lake salinity, Western Victoria, Australia: Towards a quantitative approach for reconstructing past climates. Aust. J. Bot. 1997, 45, 389-423. [CrossRef]

18. Fluin, J.; Gell, P.; Haynes, D.; Tibby, J.; Hancock, G. Palaeolimnological evidence for the independent evolution of neighbouring terminal lakes, the Murray Darling Basin, Australia. Hydrobiologia 2007, 591, 117-134. [CrossRef]

19. Wang, P.; Chappell, J. Foraminifera as Holocene environmental indicators in the South Alligator River, Northern Australia. Quat. Int. 2001, 83-85, 47-62. [CrossRef]

20. Danielopol, D.L.; Casale, L.M.; Olteanu, R. On the preservation of carapaces of some limnic ostracods: An exercise in actuopalaeontology. Hyrodbiologia 1986, 14, 143-157. [CrossRef]

21. Rosén, P.; Vogel, H.; Cunningham, L.; Reuss, N.; Conley, D.; Persson, P. Fourier transform infrared spectroscopy, a new method for rapid determination of total organic and inorganic carbon and biogenic silica concentration in lake sediments. J. Palaeolimnol. 2010, 43, 247-259. [CrossRef]

22. Rosén, P.; Vogel, H.; Cunningham, L.; Hahn, A.; Hausmann, S.; Pienitz, R.; Zolitschka, B.; Wagner, B.; Persson, P. Universally applicable model for the quantitative determination of lake sediment composition using Fourier transform infrared spectroscopy. Environ. Sci. Technol. 2011, 45, 8858-8865. [CrossRef] [PubMed]

23. Vogel, H.; Rosén, P.; Wagner, B.; Melles, M.; Persson, P. Fourier transform infrared spectroscopy, a new cost-effective tool for quantitative analysis of biogeochemical properties in long sediment records. J. Palaeolimnol. 2008, 40, 689-702. [CrossRef]

24. Smith, B.C. Fundamentals of Fourier Transform Infrared Spectroscopy, 2nd ed.; CRC Press: Boca Raton, FL, USA, 2011; p. 207.

25. Farmer, V.C. The Infra-Red Spectra of Minerals; Mineralogical Society: London, UK, 1974; p. 539.

26. Meyers, P.A.; Ishiwatari, R. Lacustrine organic geochemistry-An overview of indicators of organic-matter sources and diagenesis in lake-sediments. Org. Geochem. 1993, 20, 867-900. [CrossRef]

27. Masserschmidt, I.; Cuelbas, C.J.; Poppi, R.J.; de Andrade, J.C.; de Abreu, C.A.; Davanzo, C.U. Determination of organic matter in soils by FTIR/diffuse reflectance and multivariate calibration. J. Chemom. 1999, 13, 265-273. [CrossRef]

28. Viscarra Rossel, R.A.; McGlynn, R.N.; McBratney, A.B. Determining the composition of mineral-organic mixes using UV-vis-NIR diffuse reflectance spectroscopy. Geoderma 2006, 137, 70-82. [CrossRef]

29. Minasny, B.; Tranter, G.; McBratney, A.B.; Brough, D.M.; Murphy, B.W. Regional transferability of mid-infrared diffuse reflectance spectroscopic prediction for soil chemical properties. Geoderma 2009, 153, 155-162. [CrossRef]

30. McCarty, G.W.; Reeves, J.B., III; Reeves, V.B.; Follett, R.F.; Kimble, J.M. Mid-infrared and near-infrared diffuse reflectance spectroscopy for soil carbon measurement. Soil Sci. Soc. Am. J. 2002, 66, 640-646. 
31. Janik, L.J.; Skjemstad, J.O. Characterisation and analysis of soils using mid infrared partial least-squares. 2. Correlations with some laboratory data. Aust. J. Soil Res. 1995, 33, 637-650. [CrossRef]

32. Forrester, S.; Janik, L.; McLaughlin, M.; Soriano Disla, M.; Stewart, R.; Dearman, B. Total Petroleum Hydrocarbon Concentration Prediction in Soils Using Diffuse Reflectance Infrared Spectroscopy. Soil Sci. Soc. Am. J. 2013, 77, 450-460. [CrossRef]

33. Liu, X.; Colman, S.M.; Brown, E.T.; Minor, E.C.; Li, H. Estimation of carbonate, total organic carbon, and biogenic silica content by FTIR and XRF techniques in lacustrine sediments. J. Paleolimnol. 2013, 50, 387-398. [CrossRef]

34. Hahn, A.; Rosén, P.; Kliem, P.; Ohlendorf, C.; Persson, P.; Zolitschka, B.; the PASADO Science Team. Comparative study of infrared techniques for fast biogeochemical sediment analyses. Geochem. Geophys. 2011, 12, Q10003.

35. Veerasingam, S.; Venkatachalapathy, R. Estimation of carbonate concentration and characterization of marine sediments by Fourier transform infrared spectroscopy. Infrared Phys. Technol. 2014, 66, 136-140. [CrossRef]

36. Ji, J.; Ge, Y.; Balsam, W.; Damuth, J.E.; Chen, J. Rapid identification of dolomite using a Fourier Transform infrared spectrophotometer (FTIR): A fast method for identifying Heinrich events in IODP Site U1308. Mar. Geol. 2008, 258, 60-68. [CrossRef]

37. Janik, L.J.; Merry, R.H.; Skjemstad, J.O. Can mid infra-red diffuse reflectance analysis replace soil extractions? Anim. Prod. Sci. 1998, 38, 681-696. [CrossRef]

38. Umali, B.P.; Oliver, D.P.; Ostendorf, B.; Forrester, S.; Chittleborough, D.J.; Hutson, J.L.; Kookana, R.S. Spatial distribution of diuron sorption affinity as affected by soil, terrain and management practices in an intensively managed apple orchard. J. Hazard. Mat. 2012, 217-218, 398-405. [CrossRef] [PubMed]

39. Siebielec, G.; McCarty, G.W.; Stuczynski, T.I.; Reeves, J.B., III. Near- and mid-infrared diffuse reflectance spectroscopy for measuring soil metal content. J. Environ. Qual. 2004, 33, 2056-2069. [CrossRef] [PubMed]

40. Bertaux, J.; Frölich, F.; Ildefonse, P. Multicomponent analysis of MIRS spectra: Quantification of amorphous and crystallized mineral phases in synthetic and natural sediments. J. Sediment. Res. 1998, 68, 440-447. [CrossRef]

41. Meyer-Jacob, C.; Vogel, H.; Boxberg, F.; Rosen, P.; Weber, M.E.; Bindler, R. Independent measurement of biogenic silica in sediments by FTIR spectroscopy and PLS regression. J. Paleolimnol. 2014, 52, 245-255. [CrossRef]

42. Mecozzi, M.; Pietrantonio, E.; Amici, M.; Romanelli, G. Determination of carbonate in marine solid samples by MIR-ATR spectroscopy. Analyst 2001, 126, 144-146. [CrossRef] [PubMed]

43. Wirrman, H.; Bertaux, J.; Kossoni, A. Late Holocene palaeoclimatic changes in western central Africa inferred from mineral abundances in dated sediments from Lake Ossa (southwestern Cameroon). Quat. Res. 2001, 56, 275-287. [CrossRef]

44. Ramasamy, V.; Rajkumar, P.; Ponnusamy, V. Depth wise analysis of recently excavated Vellar river sediments through MIRS and XRD studies. Ind. J. Phys. 2009, 83, 1295-1308. [CrossRef]

45. Belzile, N.; Joly, H.A.; Li, H. Characterization of humic substances extracted from Canadian lake sediments. Can. J. Chem. 1997, 75, 14-27. [CrossRef]

46. Calace, N.; Cardellicchio, N.; Petronio, B.M.; Pietrantonio, M.; Pietroletti, M. Sedimentary humic substances in the northern Adriatic sea (Mediterranean sea). Mar. Environ. Res. 2006, 61, 40-58. [CrossRef] [PubMed]

47. Cunningham, L.; Vogel, H.; Nowaczyk, N.; Wennrich, V.; Juschus, O.; Persson, P.; Rosen, P. Climatic variability during the last interglacial inferred from geochemical proxies in the Lake El'gygytgyn sediment record. Palaeogeogr. Palaeoclim. Palaeoecol. 2013, 386, 408-414. [CrossRef]

48. Rosén, P. Total organic carbon (TOC) of lake water during the Holocene inferred from lake sediments and near-infrared spectroscopy (NIRS) in eight lakes from northern Sweden. Biogeochemistry 2005, 76, 503-516. [CrossRef]

49. Williams, W.D.; Boulton, A.J.; Taaffe, R.G. Salinity as a determinant of salt lake fauna: A question of scale. Hydrobiologia 1990, 197, 257-266. [CrossRef]

50. Wright, H.H. An improved Hongve sampler for surface sediments. J. Palaeolimnol. 1990, 4, 91-92. [CrossRef]

51. Dodson, J.R.; Mooney, S.D. An assessment of historic human impact on south-eastern Australian environmental systems using late Holocene rates of environmental change. Aust. J. Bot. 2002, 50, 455-464. [CrossRef] 
52. Haberle, S.G.; Tibby, J.; Dimitriadis, S.; Heijnis, H. The impact of European occupation on terrestrial and aquatic ecosystem dynamics in an Australian tropical rain forest. J. Ecol. 2006, 94, 987-1002. [CrossRef]

53. Leahy, P.J.; Tibby, J.; Kershaw, A.P.; Heijnis, H.; Kershaw, J.S. The impact of European settlement on Bolin Billabong, a Yarra River floodplain lake, Melbourne, Australia. River Res. Appl. 2005, 118, 111-130. [CrossRef]

54. Mooney, S.D. A fine resolution palaeoclimatic reconstruction of the last 2000 years, from Lake Keilambete, southeastern Australia. Aust. Geogr. 2001, 32, 203-212. [CrossRef]

55. Calver, M.; Lymbery, A.; McComb, J.; Bamford, M. Environmental Biology; Cambridge University Press: Melbourne, Australia, 2009; p. 744.

56. Leahy, P.; Robinson, D.; Patten, R.; Kramer, A. Lakes in the Western District of Victoria and Climate Change; EPA Publication 1359; Environment Protection Agency (Victoria): Melbourne, Australia, 2010; p. 61.

57. Barton, A.B.; Herczeg, A.L.; Dahlhaus, P.G.; Cox, J.W. A geochemical approach to determining the hydrological regime of wetlands in a volcanic plain, south-eastern Australia. In Groundwater and Ecosystems; IAH Selected Papers on Hydrogeology Series 18; Ribeiro, L., Stigter, T.Y., Chambel, A., Condessa de Melo, M.T., Moneiro, J.P., Medeiros, A., Eds.; CRC Press (Taylor \& Francis): Boca Raton, FL, USA; pp. 365-373.

58. Madejová, J. MIRS techniques in clay mineral studies. Vib. Spectrosc. 2003, 31, 1-10. [CrossRef]

59. Sivakumar, S.; Ravisankar, R.; Chandrasekaran, A.; Prince Prakash Jebakumar, J. FT-IR Spectroscopic Studies on Coastal Sediment Samples from Nagapattinum District, Tamilnadu, India. Int. Res. J. Pure Appl. Chem. 2013, 3, 366-376. [CrossRef]

60. Andrews, J.E.; Briblecomb, P.; Jickells, T.F.; Liss, P.S.; Reid, B.J. An Introduction to Environmental Chemistry; Blackwell Publishing: Malden, MA, USA, 2004.

61. Huggert, R.J. Fundamentals of Geomorphology; Routledge: Milton Park, UK, 2007.

62. Weaver, C.E. Clays, Muds and Shales; Development in Sedimentology, 44; Elsevier: Amsterdam, The Netherlands, 1989.

63. National Climate Centre (NCC). Special Climate Statement 22: Australia's Wettest September on Record but It Is Not Enough to Clear Long-Term Rainfall Deficits; Bureau of Meteorology: Melbourne, Australia, 2010; p. 10.

(C) 2016 by the authors; licensee MDPI, Basel, Switzerland. This article is an open access article distributed under the terms and conditions of the Creative Commons Attribution (CC-BY) license (http://creativecommons.org/licenses/by/4.0/). 